\title{
TRANSGENIC COTTON: HARBORING BROAD TERM RESISTANCE AGAINST INSECT AND WEEDS THROUGH INCORPORATION OF CEMB DOUBLE Bt AND cp4EPSPS GENES
}

\author{
Mudassar Fareed Awan ${ }^{1}$, Arfan Ali ${ }^{1,2 *}$, Adnan Muzaffar ${ }^{1}$, Malik Adil Abbas ${ }^{1}$, Abdul Qayyum Rao ${ }^{1}$, Zahida \\ Qamar', Shahid Javed Butt ${ }^{3}$, Ghazanfar Ali Khan ${ }^{4}$, Bushra Rashid ${ }^{1}$, Idrees Ahmad Nasir' ${ }^{1}$ and Tayyab \\ Husnain
}

\author{
${ }^{1}$ Centre of Excellence in Molecular Biology, (CEMB) University of the Punjab Lahore 53700, Pakistan; ${ }^{2}$ Institute of Molecular \\ Biology and Biotechnology, The University of Lahore; ${ }^{3}$ University of Management and Technology, Sialkot Campus- \\ Sialkot $;{ }^{4}$ Development and planning wing, Department of Agriculture Punjab Lahore, Pakistan. \\ *Corresponding author's e-mail: arfan.ali@cemb.edu.pk
}

\begin{abstract}
Introduction of multiple traits in crop plants for desirable character is an essential tool of Biotechnological application. To overcome problem of insect pests and weeds cotton variety FBS-37 was genetically modified by transformation of CEMB Cry1Ac+Cry2A and GTGene cloned in different plant expression vectors under CaMV35S Promoter and nopaline synthase Nos Terminator. CEMB optimized protocol of cotton gene transformation i.e. Agrobacterium mediated shoot apex cut method was applied for transformation of these genes constructs in cotton. Overall transformation efficiency was found to be $1.05 \%$. Putative transgenic cotton plants were shifted to soil pots and acclimatized in the green house conditions. PCR with gene specific primers amplified 190bp for EPSPS (Glyphosate GTG) and $1000 \mathrm{bp}$ for each of Cry1Ac and Cry2A. Quantification of Cry1Ac, Cry2A and GTG protein through ELISA determined maximum of $0.8 \mu \mathrm{g} / \mathrm{g}, 1 \mu \mathrm{g} / \mathrm{g}$ and $0.9 \mu \mathrm{g} / \mathrm{g}$ of tissue respectively. $100 \%$ mortality was obtained in $2^{\text {nd }}$ instar larvae of Heliothus armigera when compared with non-transgenic control cotton plants where maximum damaged was seen in leaf bioassay. Moreover, transgenic cotton plants successfully survived when sprayed with $1600 \mathrm{ml} /$ acre of glyphosate as compared to control where $100 \%$ mortality and necrosis occur after 7 days of spray assay in control conditions.
\end{abstract}

Keyword: Herbicide resistant, glyphosate, Cryl Ac, GTG, weedicide resistant

\section{INTRODUCTION}

Cotton is the backbone of economy and employment in Pakistan. The sector employs about $40 \%$ of total force and earns approximately US $\$ 15$ billion (Vogel, 2014). Nearly $45-60 \%$ of foreign exchange has been procured due to production and consumption of cotton (Batool et al., 2010; Khan et al., 2013; Khan and Khan, 2003). Pakistan being fourth largest producer of cotton suffered $14 \%$ of the losses in total agriculture due to insect pest of which $84 \%$ is in cotton (Shahid et al., 2012; Awan et al., 2015; Bale et al., 2008), 25\% yield losses occur due to weeds (Khan and Khan, 2003) while remaining 30\% losses occur due to $\mathrm{CLCuV}$ (Farooq et al., 2011) and 25\% by abiotic factors. Initially, pre-sowing applications are applied to eliminate weeds already present and those that will appear before the crop (Farroq and Cheema, 2014.

Manual hoeing was the only reliable alternative for getting rid of weeds in the past, but it was time consuming and labour intensive (Cheema et al., 2005). Total weed seed numbers in the soil was found to rise significantly after shifting from conventional chemical weed control to nonchemical means (Bond and Grundy, 2001). Hence, total effort required using non-chemical methods are not viable or economically sustainable. Biotechnology provides a tool through which, this can happen easily compared with conventional method. Glyphosate (Nphosphonomethylglycine) belongs to herbicide group 'glycines' which is a broad-spectrum universal herbicide used to kill annual broad leaf weeds and grasses which are known to compete with commercial crops grown around the World. Glyphosate affects in the shikimate metabolic pathway by preventing the synthesis of 5-enolpyrovyle 3phosphoshikimate (EPSPS). It inhibits the synthesis of three aromatic amino acids including tryptophan, phenylalanine and trypsin (Yamada et al., 2009).

Resistance against insect pests and herbicide has been attained in high yield varieties by different ways now-a-days (Khan et al., 2014). Conventional breeding though necessary but takes much time to attain main objective. Genetic engineering is also a modern way of breeding that guarantees to avoid the problems related with the transfer of large blocks of genetic materials between two parents (Bajaj, 1998).

Genetic transformation of plants methodologies have been developed to upturn the efficiency of transformation and to 
achieve stable expression of trans-genes in plants. In the present study, genes (Cry1Ac+Cry2A) and Glyphosate (GTG) that have resistance against the insect pests and weeds respectively were transformed in the cotton variety FBS-37 through Agrobacterium tumifaciens.

\section{MATERIALS AND METHODS}

Plant material: Cotton variety FBS-37 was selected for transformation of Cry1Ac+Cry2A genes along with cp4EPSPS genes because of its high germination. The seeds of cotton variety FBS-37 were collected from four brothers research station Multan. Delinting of cotton seeds was done by using concentrated $\mathrm{H}_{2} \mathrm{SO}_{4}$ while sterilization with $5 \%$ (W/V) $\mathrm{HgCl}_{2}$ and $10 \%$ (w/v) SDS followed by 5-6 washings with autoclaved distilled water. Afterward, seeds were allowed to germinate by incubation at $30^{\circ} \mathrm{C}$ for 48 hours.

Transformation of cotton variety $\mathrm{FBS}-37$ with Cry1Ac + Cry $2 A$ and CP4EPSPS gene: Transformation of Cry1Ac + Cry2A and cp4 EPSPS gene in cotton variety FBS-37 was done by following the method as done by (Rao et al., 2011). Two constructs containing CaMV 35S constitutive promoter and Nos terminator were used for transformation of cotton. Screening of putative transgenic plants was done on kanamycine at the rate $(50 \mathrm{mg} / \mathrm{ml})$ medium for two months, putative transgenic plants were shifted to selection free medium for shoot and root formation, as determined by Rao et al. (2009).

Isolation of DNA from putative transgenic cotton plants and confirmation through PCR: Isolation of DNA from screened cotton plants was done by taking the fresh leaves and following the protocol described by (Lenin et al., 2001). Reaction mixture for PCR was prepared by using 10X PCR Buffer $(2 \mu \mathrm{l})$ with $2.5 \mathrm{mM} \mathrm{MgCl}_{2}(2 \mathrm{ul}), 300$ ng DNA template $(1.5 \mu \mathrm{l}), 1 \mathrm{mM}$ dNTPs $(2 \mu \mathrm{l}), 10$ picmole primers $(2 \mu \mathrm{l})$ (forward and reverse) and 2.5U Taq DNA Polymerase for total volume of $20 \mu \mathrm{l}$. The reaction was proceeded in ABI 9700 thermocycler having following conditions, initial denaturation at $94^{\circ} \mathrm{C}$ for 5 min followed by 35 cycles of denaturation at $94^{\circ} \mathrm{C}$ for $1 \mathrm{~min}$, annealing at $51^{\circ} \mathrm{C}$ for Cry $2 \mathrm{~A}$ and GTGenewhile $50^{\circ} \mathrm{C}$ for Cry $1 \mathrm{Ac}$ for $1 \mathrm{~min}$ followed by extension at $72^{\circ} \mathrm{C}$ for $3 \mathrm{~min}$. Final extension was done at $72^{\circ} \mathrm{C}$ for 5 minutes. PCR amplified products were resolved on $1 \%(\mathrm{w} / \mathrm{v})$ agarose gel and visualized by ethidium bromide staining.

Enzyme Linked Immuno Sorbent Assay (ELISA) of transgenic cotton plants: Cry1Ac, Cry2A and GTGene expression was evaluated through Enzyme Linked Immuno Sorbent Assay (ELISA) by using Envirologix Kit (Cat \# 051). One gram leaves samples of transgenic cotton plants were taken in liquid nitrogen and ground to fine powder in pestle morator. $600 \mu \mathrm{l}$ of protein extraction buffer $(0.5 \mathrm{M}$ EDTA, Glycerol, 5M NaCl, 2M Tris-Cl, NH4Cl, PMSF,
DTT) was added in the fine powder followed by incubation of $1 \mathrm{hr}$ on ice and centrifugation at $13000 \mathrm{rpm}$ for $25 \mathrm{~min}$.

Evaluation of Cry1Ac and Cry2A Toxicity through leaf bioassay: The transgenic cotton plants leaves were subjected to $2^{\text {nd }}$ instar larvae of Helicoverpa armigera. Total five leaves from upper, middle and lower part of the transgenic cotton plants of 30, 60 and 90 day old (transformed and control, non-transgenic) were taken. The leaves were placed on moist filter paper present in petri plates. $2^{\text {nd }}$ instar larvae of Heliothis were placed on the leaves for 2-3 days and their feeding was recorded. Insect mortality data was collected after 2-3 days feeding of insect on both transgenic and control plants.

Evaluation of herbicide tolerance of transgenic cotton plants through glyphosate spray assay: Total $1600 \mathrm{ml} /$ acre Glyphosate was applied to transgenic cotton plants in comparison to control. Herbicide Glyphosate is commercially available as Roundup ${ }^{\mathrm{TM}}$. Glyphosate was prepared up to final concentration of $1600 \mathrm{ml} / 80 \mathrm{~L}$ by dissolving it in water. Mixture was applied $(1600 \mathrm{ml} / \mathrm{acre})$ to field grown transgenic cotton plants along with control nontransgenic cotton plants.

Table 1. Primer sequences used in the study:

\begin{tabular}{llc}
\hline Primer & \multicolumn{1}{c}{ Sequence (5'-3') } & Size \\
\hline Cry2A-F & AGATTACCCCAGTTCCAGAT & $600 \mathrm{bp}$ \\
Cry2A-R & GTTCCCGAAGGACTTTCTAT & \\
GTG-F & CCCTGGTGACAAGTCCATCT & $358 \mathrm{bp}$ \\
GTG-R & CTGCACACCCATCTCTCTGA & \\
Cry1Ac-F & ACAGAAGACCCTTCAATATC & $565 \mathrm{bp}$ \\
Cry1Ac-R & GTTACCGAGTGAAGATGTAA & \\
\hline
\end{tabular}

\section{RESULTS}

Genetic transformation of cotton variety FBS-37: Cotton variety FBS-37germination index was found to be $66.6 \%$. Genetic transformation of cotton variety FBS-37 resulted in the development of 50 plantlets on selection medium after two month of screening through kanamycin. The overall transformation efficiency was found to be $1.05 \%$.

Evaluation of putative transgenic cotton plants through molecular analysis: Putative transgenic cotton plants were evaluated for (cp4EPSPS) GTGene through PCR. 190bp fragment was amplified fop GTGene by using gene specific primers Figure 1. Similarly, 1000bp fragment was amplified for each of Cry1Ac and Cry2A as shown in Figure 2 and 3, respectively. Transgenic cotton plants namely V4, V5, V7, V8, V9, V10 and V11 were confirmed positive not only for GTGene but also for CEMB- double Bt genes while no amplification was seen in negative control Figure 2, 3 and 4. The results of ELISA by using Envirologix kit clearly demonstrate successful expression of GTGene, Cry1Ac and Cry2A gene, respectively. Quantification of Cry1Ac, Cry2A 
and GTG protein through ELISA determined maximum of $0.8 \mu \mathrm{g} / \mathrm{g}, 1 \mu \mathrm{g} / \mathrm{g}$ and $0.9 \mu \mathrm{g} / \mathrm{g}$ of tissue, respectively (Fig. 4).

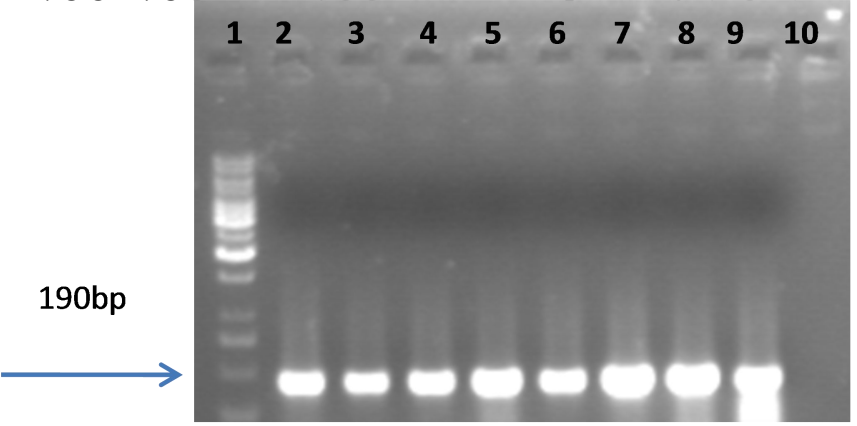

Figure 1. Amplification of cpEPSPS gene in transgenic cotton plants. Lane $11 \mathrm{~kb}$ plus DNA Ladder, Lane 2-8 Transgenic cotton plants (V4, V5, V7, V8, V9, V10 and V11), Lane 9. Positive control plasmid, Lane 10. Negative control non transgenic cotton plant

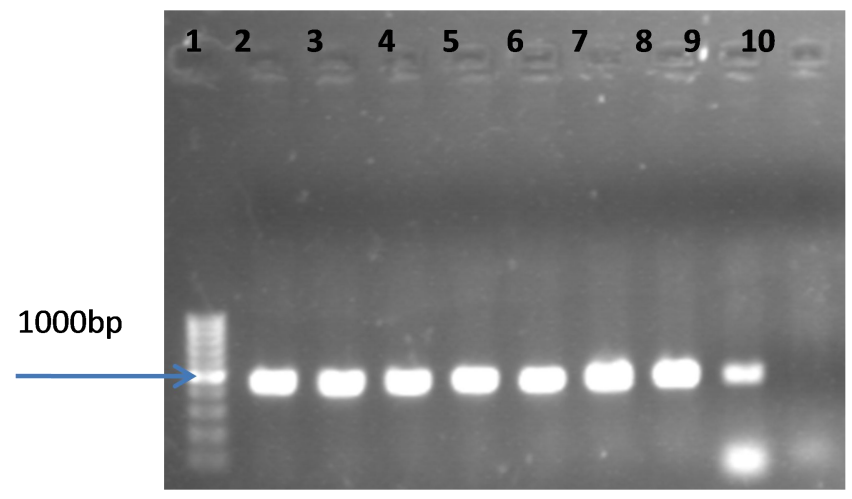

Figure 2. Amplification of Cry1Ac gene in transgenic cotton plants. Lane $11 \mathrm{~kb}$ plus DNA ladder, Lane 2-8 transgenic cotton plants (V4, V5, V7, V8, V9, V10 and V11). Lane 9. Positive control plasmid, Lane 10. Negative control non transgenic cotton plant

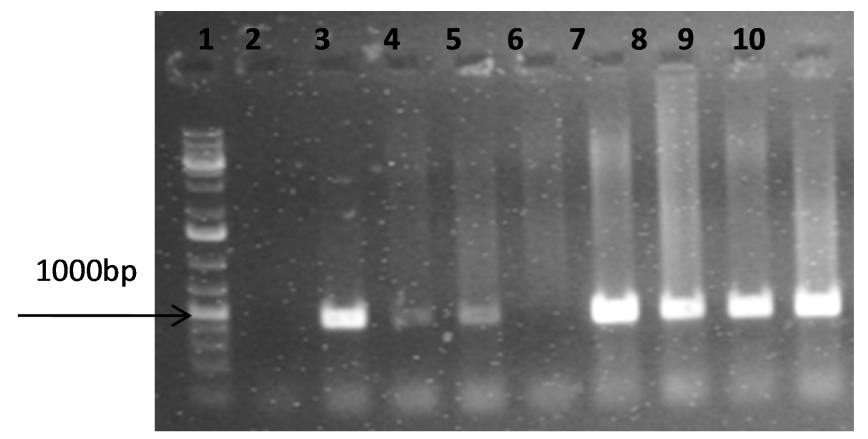

Figure 3. Amplification of Cry2A gene in transgenic cotton plants. Lane $11 \mathrm{~kb}$ plus DNA Ladder, Lane 2. Negative control non transgenic cotton plant, Lane 3. Positive control plasmid, Lane 4-10
Transgenic cotton plants (V4, V5, V7, V8, V9, V10 and V11)

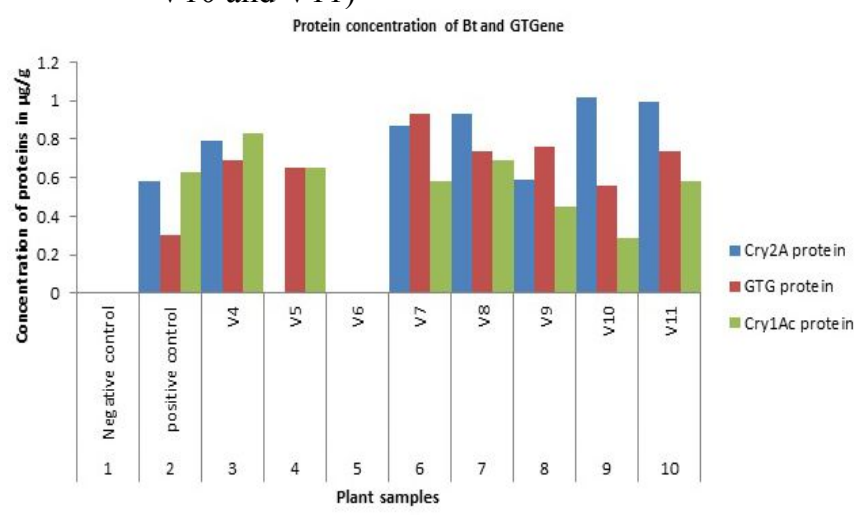

Figure 4. Graphical representation of quantification of GTG and Bt proteins.

Determination of efficacy of Cry1Ac and Cry2A through leaf bioassay of insects: Mortality percentage of Heliothus armigera $2^{\text {nd }}$ larvae was found variable after 30,60 and 90 days due to variation in level of expression at different time of growth of plants. Both dead and alive larvae were counted in each petri plate. Mortality $90-100 \%$ of larvae was found in larvae fed on transgenic plant leaves while no mortality was found in larvae fed on leaves of non- transgenic control plants and insects remain healthy and also advances their cycle to next instar (Fig. 5).

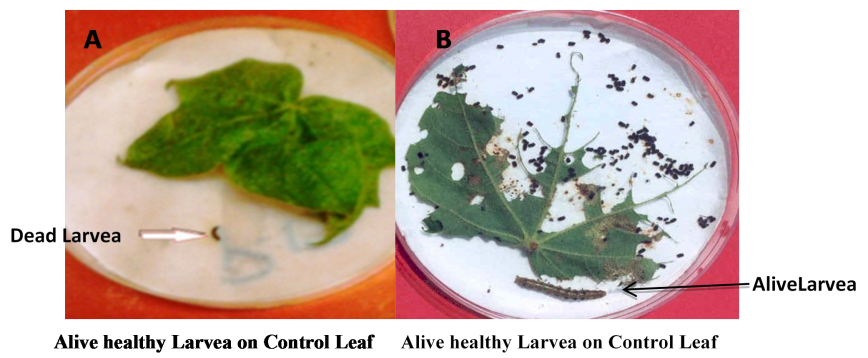

Figure 5. Bioassay of transgenic and control plant leaves.

A. A transgenic plant leaf and larva is killed after eating a small portion of leaf.

B. A control non-transgenic plant. Larva ate it and is alive.

Determination of herbicide resistance of transgenic cotton plants through glyphosate spray assay: Transgenic cotton plants were sown in field containment and no application of weed removal was applied until 3 months. After three months when cotton field was full of different kinds of weeds glyphosate spray at the rate of $1600 \mathrm{ml} /$ acre was applied. The necrotic effect of glyphosate became visible after 3-5 days post herbicide application (Fig. 6A, B). Symptoms which appear comprised of wilting, drooping and slight burning spot appearance and ultimate death of all 
weeds along with non-transgenic control cotton plants (Fig. $6 \mathrm{~B})$.

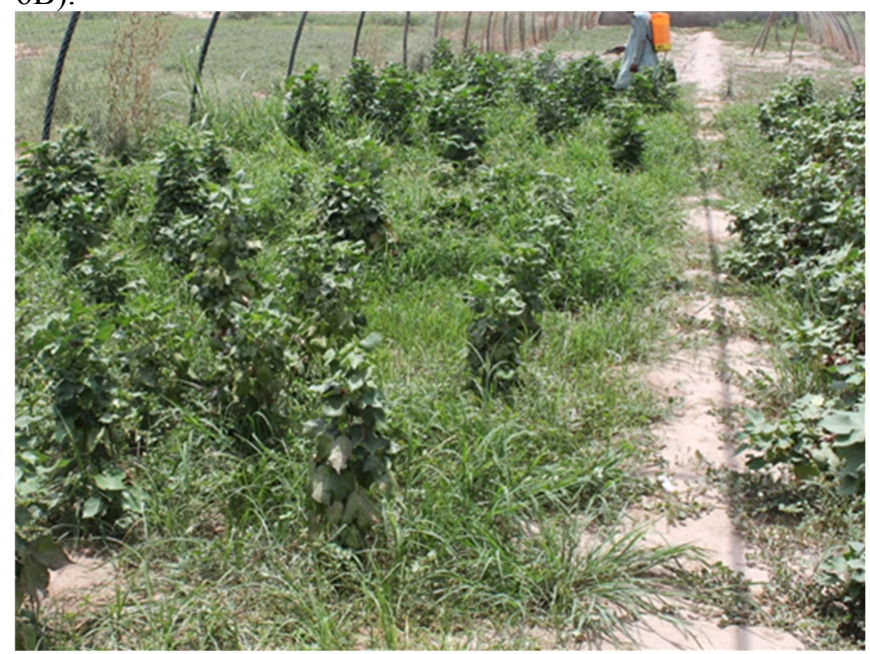

Figure 6A. Field spray assay: Presence of weeds in field along with control and transgenic plants. Glyphosate was being sprayed.

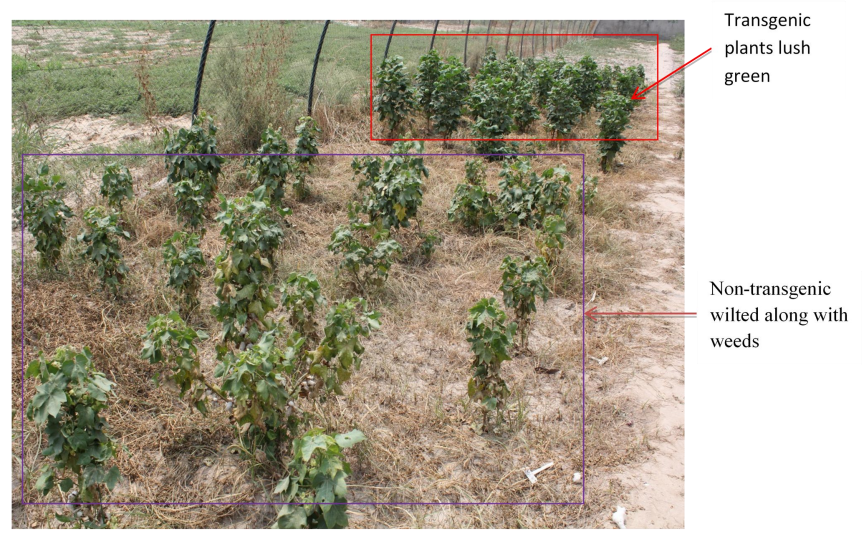

Figure 6B. After five days weeds and control plants were dead while transgenic plants were healthy. It shows the presence of GTGene in cotton plants.

\section{DISCUSSION}

Cotton plays very significant role in economy of Pakistan by generating $30 \%$ of foreign exchange and contributing $80 \%$ of raw material to textile industry. Despite of its importance cotton is being harmed by attack of different insect pests and weeds. Total $20 \%$ yield losses in cotton occur due to insect pests (Gruere et al., 2011) while $25 \%$ of yield losses in cotton occur due to weeds (Khan et al., 2003; Monks et al., 2007;). To overcome such losses an attempt was made in current study to develop insect and herbicide resistant cotton plants by introduction of Cry1Ac +Cry $2 \mathrm{~A}$ as done by Muzaffar et al. (2015) and cp4EPSPS gene as done by Awan et al. (2015).
Transformation of double Bt and GTGene was done by shoot apex cut method as done by Rao et al. (2011). Transformation efficiency of experiments was calculated to be $1.05 \%$ which is almost similar to the results obtained by Bakhsh et al. (2012); Rao et al. (2011). Amplification of $190 \mathrm{bp}$ fragment for GTGene and 1000bp for each of Cry1 Ac + Cry2A confirmed successful transformation of three gene in cotton variety FBS-37 conferring resistance to the broadspectrum glyphosate and insects, respectively (Ali et al,(2016); Rao et al., 2013).

The results of ELISA of Bt and GTGene in transgenic cotton plants confirmed their successful expression. Quantification of Cry1Ac, Cry2A and GTG protein through ELISA determined maximum of $0.8 \mu \mathrm{g} / \mathrm{g}, 1 \mu \mathrm{g} / \mathrm{g}$ and $0.9 \mu \mathrm{g} / \mathrm{g}$ of tissue, respectively (Fig. 4). The efficacy of transgenes in transgenic plants were further confirmed by insect bioassay and glyphosate spray assay as shown in Figure 5 and 6, respectively. Mortality of insects $(100 \%)$ on transgenic cotton plant leaves while complete survival on nontransgenic control plant leaves determined successful expression of Cry1Ac +Cry2A genes as was obtained by Kiani et al. (2013). Similarly, complete survival of transgenic cotton plants against $1600 \mathrm{ml} /$ acre glyphosate spray in comparison to control and weeds where $100 \%$ death was obtained and determines efficacy of transgene cpEPSPS against glyphosate herbicide. The results are in accordance as obtained by Zhao et al. (2011) and Awan et al. (2015).

Conclusion: FBS-37 harboring CEMB Cry1Ac + Cry2A genes along with cp4EPSPS gene holds good potential to combat with serious problems of insects and weeds. It may be proved to be a good asset for national breeders to utilize this material for development of high yielding insect and weedicide resistant cotton varieties which can pave their role in boosting up of national economy.

\section{REFERENCES}

Ali, A., Ahmad, S., Ahmad Nasir, I., Qayyum Rao, A. and Husnain, T., 2016. Evaluation of two cotton varieties CRSP1 and CRSP2 for genetic transformation efficiency, expression of transgenes Cry1Ac+ Cry2A, GT gene and insect mortality. doi:10.1016/j.btre.2016.01.001Biotech. Rep.

Awan, M.F., M.A. Abass, A. Muzaffar, A. Ali, B. Tabassum, A.Q. Rao and T. Husnain. 2015. Transformation of insect and herbicide resistance genes in cotton (Gossypium hirsutum L.). J. Agri. Sci. Technol. 17:287298.

Bajaj, Y.P.S. 1998. Biotechnology in Agriculture and Forestry (cotton). Springer, Berlin.

Bakhsh, A., S. Siddique and T. Husnain. 2012. A molecular approach to combat spatio-temporal variation in 
insecticidal gene (Cry1Ac) expression in cotton. Euphytica 183:65-74.

Bale, J.S., J.C. Van Lenteren and F. Bigler. 2008. Biological control and sustainable food production. Philosophical Transactions of the Royal Society B: Biol. Sci. 363:761776.

Batool, S., N.U. Khan and K. Makhdoom. 2010. Heritability and genetic potential of upland cotton genotypes for morpho-yield traits. Pak. J. Bot. 42:1057-1064.

Bond, W. and A. Grundy. 2001. Non-chemical weed management in organic farming systems. Weed Res. 41:383-405.

Cheema, M.S., M. Akhtar and M.S. Iqbal. 2005. Evaluation of chemical, mechanical and manual weed control methods in cotton. Pak. J. Weed Sci. Res. 11:47-50.

Farooq, A., J. Farooq, A. Mahmood, A. Shakeel, A. Rehman, A. Batool, M. Riaz, M.T.H. Shahid and S. Mehboob. 2011. An overview of cotton leaf curl virus disease $(\mathrm{CLCuD})$ a serious threat to cotton productivity. Aust. J.Crop Sci. 5:1823-1831.

Farooq, O. and Z.A. Cheema. 2014. Influence of sowing dates and planting methods on weed dynamics in wheat crop. Pak. J. Agri. Sci. 51:817-825.

Gruere, G. and D. Sengupta. 2011. Bt cotton and farmer suicides in India: An evidence-based assessment. The J. Dev. Stud. 47.2:316-337.

Khan, G., A. Bakhsh, M. Ghazanfar, S. Riazuddin and T. Husnain 2013. Development of transgenic cotton pure lines harboring a pesticidal gene (cry1Ab). Emirates J. Food Agri. 25:434-442.

Khan, M.A., A. Ali, M .Aslam, Z. Tahir, M.M. Khan and I. Nadeem. 2014. The role of morphological and chemical plant traits imparting resistance in Bt cotton genotypes against thrips, Thrips tabaci (Lind.). Pak. J. Agri. Sci. 51:725-731.

Khan, N.U and S.U. Khan. 2003. Integrated weed management in upland cotton. Pak. J. Weed Sci. Res. 9:185-192.

Kiani,S., Ali,A., Bajwa, K.S., Muzaffar, A., Ashraf,M.A., Samiullah,T.R., Shahid, A.A., Husnain,T. 2013 Cloning and Chloroplast-targeted Expression Studies of
Insect-resistant Gene with Ricin Fusion-Gene under Chloroplast Transit Peptide in Cotton. Electronic journal of Biotechnology Vol. 16:1-14.

Lenin, K., M.A. Mariam and V. Udayasuriyan. 2001. Expression of a cry2Aa gene in an acrystalliferous Bacillus thuringiensis strain and toxicity of Cry2Aa against Helicoverpa armigera. World J. Microb. Biot. 17:273-278.

Monks, C.D., G. Wehtje, C. Burmester, A.J. Price, M.G. Patterson, D.P. Delaney, W. Faircloth and M.R. Woods. 2007. Glyphosate-resistant cotton response to glyphosate applied in irrigated and nonirrigated conditions. Weed Technol. 21:915-921.

Muzaffar, A., S. Kiani, M.A.U. Khan, A.Q. Rao, A. Ali, M.F. Awanand and T. Husnain. 2015. Chloroplast localization of Cry1 Ac and Cry2A protein-an alternative way of insect control in cotton. Biol. Res. 48:1-11.

Rao, A.Q., A. Bakhsh, I.A Nasir, S. Riazuddin and T. Husnain. 2013. Phytochrome B mRNA expression enhances biomass yield and physiology of cotton plants. Afr. J. Biotechnol. 10:1818-1826.

Rao, A.Q., A. Bakhsh, S. Kiani, K. Shahzad, A.A. Shahid, T. Husnain and S. Riazuddin. 2009. The myth of plant transformation. Biotechnol. Adv. 27:753-763.

Rao, A.Q., M. Irfan, Z. Saleem, I.A. Nasir, S. Riazuddin and T. Husnain. 2011. Overexpression of the phytochrome B gene from Arabidopsis thaliana increases plant growth and yield of cotton (Gossypium hirsutum). J. Zhej. Univ. Sci. B. 12:326-334.

Shahid, M.R., J. Farooq, A. Mahmood, F. Ilahi, M. Riaz, A. Shakeel, I.V. Petrescu-Mag and A. Farooq. 2012. Seasonal occurrence of sucking insect pest in cotton ecosystem of Punjab, Pakistan. Adv. Agri. Botanics. 4:26-30.

Vogel, H.L.2014. Entertainment industry economics: A guide for financial analysis. Cambridge University Press.

Yamada, T., R.J. Kremer, P.R. de Camargo e Castro and B.W. Wood. 2009. Glyphosate interactions with physiology, nutrition, and diseases of plants: Threat to agricultural sustainability. Eur. J. Agron. 31:111-113.

Zhao, T., C. Lin and Z. Shen. 2011. Development of transgenic glyphosate-resistant rice with G6 gene encoding 5-Enolpyruvylshikimate-3-Phosphate synthase. Agri. Sci. China 10: 1307-1312. 